\title{
Perceptions Between Medicine Students on the Use of Anatomage and Other Practice Methods for Anatomy Teaching
}

\author{
Jesús García Martín*, Lorenzo Mauricio Hernández Fernández and Ana Slocker de Arce \\ Department of Surgery and Social and Medical Sciences, Unit of Human Anatomy and Embryology, Faculty of Medicine and Health \\ Sciences, University of Alcalá. Alcalá de Henares. 28805 - Madrid, Spain \\ *Corresponding author: Jesús García Martín, Department of Surgery and Social and Medical Sciences, Unit of Human Anatomy and \\ Embryology, Professor of Human Anatomy and Embriology, Faculty of Medicine and Health Sciences, University of Alcalá, 28047 - \\ Madrid, Spain, Tel: 34-635 239494 - 34-91-885 4878; Fax: 34-91-885-4593; Email: jesus.garcia@uah.es
}

\section{ARTICLE INFO}

Received: 㓞 December 16, 2019

Published: 幽 January 10, 2020

Citation: García Martín, J. Hernández Fernández, L.M. Slocker de Arce, A. (2020) . Perceptions Between Medicine Students on the Use of Anatomage and Other Practice Methods for Anatomy Teaching. Biomed J Sci \& Tech Res 24(3)-2020. BJSTR. MS.ID.004065.

Keywords: Anatomy; Practice; Education; Dissection; Anatomage; Anatomical Models; Skeleton

Abbreviations: A: Anatomage; AA: Anatomy Atlases; AM: Anatomical Models; BS: Bones and Skeleton PS: Prossections and Dissections.

\section{ABSTRACT}

Introduction: To know the usefulness, interests and preferences of a group of medical students, with some practical methods for teaching Anatomy, we designed a survey.

Material and Methods: This is a numerical scale containing 5 scores and 5 items or methods to assess the level of interest and usefulness experienced by students. The different methods included in the study and used to teach practical human anatomy range from the anatomy atlases, bones and skeleton, anatomical models, prossections and dissections and the newest and most sophisticated, the 3D virtual anatomical table: Anatomage.

Result: Prossections and dissections were the most valued of all practice methods with significant differences of $p<0,000$ with the Anatomage being the least valued. The students found the prossections very useful in percentage of 46.9 and only $6.2 \%$ of them found the Anatomage very useful. Intermediate scores were observed among the other practice methods.

Discussion: These techniques have advantages and weaknesses. Anatomical models give students a good three-dimensional perspective and relationships between internal organs and structures. The Anatomage allows teaching and learning anatomy interactively with students who can explore the inner parts of the human body and rebuild it again.

\section{Short Communication}

One of the most important subjects in medical education is the human anatomy. A good background in anatomy prepares the students for future in clinical disciplines and human body dissection has been used as the mean teaching tool. Also a good knowledge in anatomy can guarantee a safe and efficient clinical practice [1]. The cultural, scientific advances and new trends in medical education have altered the role of dissection in the teaching of anatomy in medical schools today [2,3]. It is true that in the past, lectures and cadaver dissection by students was considered as essential to anatomy learning. And anatomists and clinicians worry about the adverse effect on students' knowledge when decreasing

the time-related to the cadaver dissection from anatomy education [4]. Using three-dimensional models is useful to understand the volumes of the body regions. They are also valuable for better interpretation of X-ray, ultrasound and sectional images [5]. The performance of medical students improved in human anatomy significantly with the use of computer tomography and life-size tablets for virtual dissection. What it is important, that medical images and virtual dissection should be included as part of the basic anatomy curriculum [6]. The Anatomage Table is becoming an additional component of anatomical courses for medical studies. It offers a unique digital teaching platform and digital Anatomy 
offers various benefits. This system will not only assist students to learn anatomical details, but also provide the appreciation of 3D structures. It can help young students to learn the complex anatomy structure and their special relationship better and faster than only using traditional methods [7].

\section{Material and Methods}

Classically and nowdays we are using different methods to teach practical human anatomy. We included in this survey five techniques: Anatomage (A) - Anatomy Atlases (AA) - Anatomical Models (AM) - Bones and Skeleton (BS) - Prossections and Dissections (PS). The survey was an item scale with five numeric values which extents from: 1. No useful, 2. Less useful, 3. Indiferent, 4. Useful, 5. Very useful. We use a Google Forms model. The survey was sent to a group of second-year students who were preparing as military doctors at the University Defense Center located in Madrid. At the end, we got a total of 32 good and complete surveys. Our goal was to evaluate the level of interest and usefulness experienced by students using these techniques. Statgraphics Centurion XV was used for statistical analysis. For each of the methods of practice evaluated and described above, an analysis of variance (ANOVA) was performed to determine whether there are significant differences between the corresponding means to the value of interest and usefulness students experience when studying these five different anatomical methods. To calculate which means are significantly different from others with a 95.0\% confidence level, Fisher's least significant difference (LSD) method was used.

\section{Result}

In the ANOVAS analyzed, significant differences have been found with a level of $\mathrm{P}<0.000$ between the Anatomage and all the other methods studied. Prossections and dissections were the most valued of all the practice methods with significant differences of $p<0,000$ with the Anatomage that was the less valued. No differences were found among prossections and dissections and the other practice methods studied as the anatomy atlases, anatomical models and the bones and skeleton.46,9\% of the students found very useful the prossections and dissections and only $6,2 \%$ of them found very useful the Anatomage. The anatomy atlases and the anatomical models were valued by $34,4 \%$ of the students as very useful and only $15,6 \%$ gave the same score to the bones and skeleton (Figure 1).

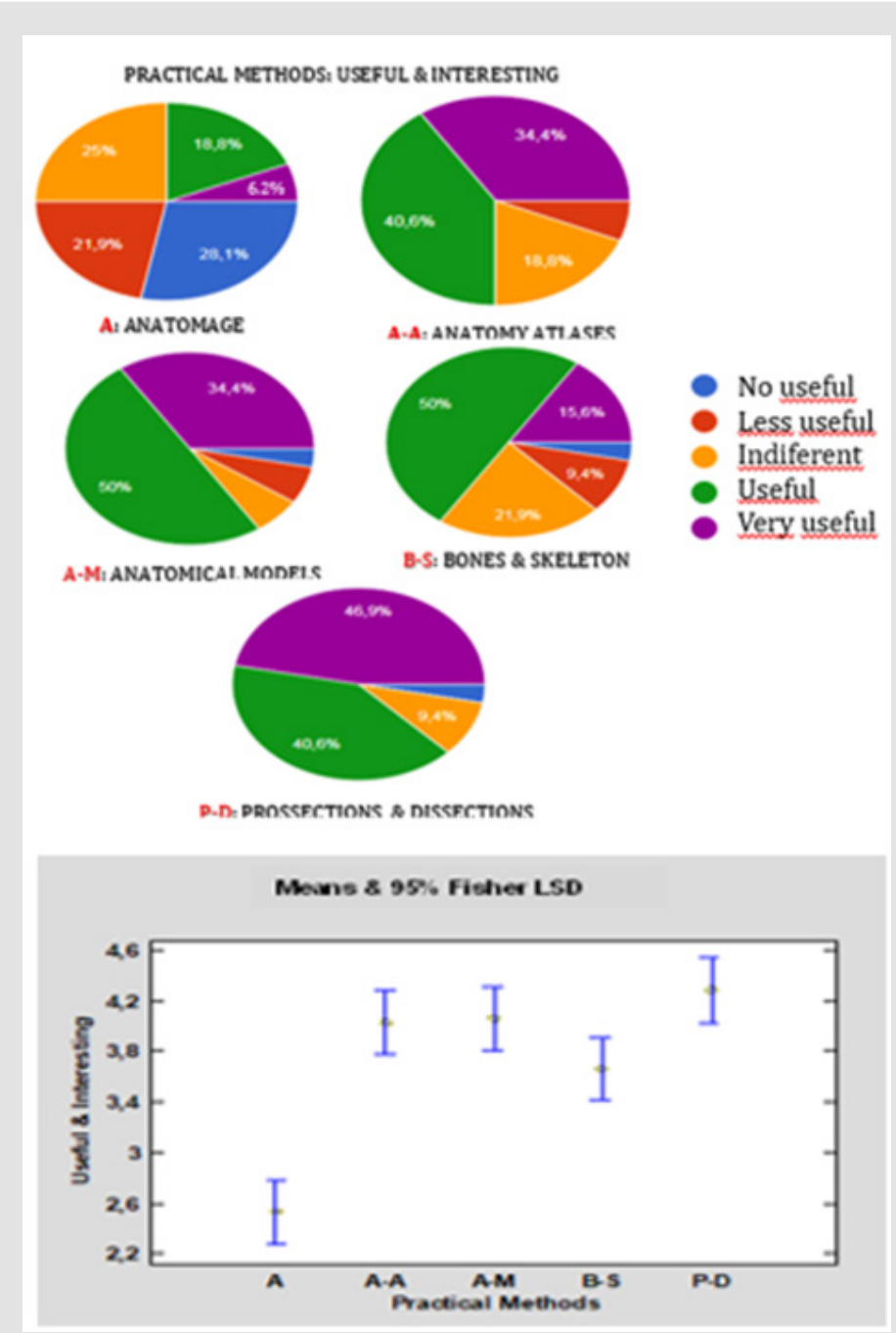

Figure 1: Practice Methods: Useful \& Interesting; ANOVA for the 5 different Practice Methods. 


\section{Discussion}

Patel. \& Moxham (2006) state that recent developments in the medical curriculum have led to marked changes in the teaching of macroscopic anatomy. This change has implied a decrease in the curricular contact time of the students with the human body and the use of new methods for anatomical teaching. Some "modern" anatomists have welcomed the arrival of these novel methods, while other more "traditional" anatomists have struggled to maintain the use of cadaveric dissection. After studying these changes with a questionnaire, the authors observed that $98 \%$ of anatomists think that gross anatomy plays an important role in clinical medicine. And $69 \%$ of them support the use of dissection [8]. Moxham \& Plaisant (2007) investigated the perception of medical students towards the importance of macroscopic anatomy to clinical medicine. Students at all stages of their medical course share with professional anatomists the view that anatomy is a very important subject for their clinical studies [9]. Patel \& Moxham [10]) on 2008 observedthat a majority of anatomistsare in favour to the use of dissection, specially to gain skills by the students.

Cadaver dissection is an irreplaceable part of anatomy education to enrich the student experience and knowledge. The prossection and dissection are necessary to appreciate the complexity and multidimensionality of the human body, and to learn the basic language of medicine [11]. Pabst [12] on 2009 considered about the anatomy curriculum, that dissection is very important, but the main matter in the medical curriculum is to prepare a well-trained doctor. Anatomage-based training has proven to be effective. It has been observed that more publications appear with greater student acceptance, achieving better test scores, with more effective practice sessions in the classroom and laboratory. The precise details and rich content attract the interest and attention of students, leading to more effective learning outcomes as Professor Duparc points out [13]. The use of cadaver CT scans and full-size virtual dissection tables significantly improved the performance of medical students in gross anatomy. Therefore, medical imaging and virtual dissection should be considered part of the standard curriculum of macroscopic anatomy $[6,13]$.

Custer and Michael [14] concluded that students appreciate learning with this technology and think it is a beneficial and effective tool to prepare them to enter a healthcare profession. In addition, the table allows exploration and learning of human anatomy and experience simulation of easy surgical procedures. It is possible to cut from the surface of the body to the inner body with a scalpel, as well as to view images of three-dimensional sections in all three spatial planes $[15,16]$. The controversy arises when the Anatomage is compared with other traditional methods of teaching anatomy such as dissection. A year ago we published an article based solely on an observational and subjective analysis from impressions about the advantages of using Anatomage for easier learning of anatomy practice by students. We observe very interested and highly motivated students to study the different practices taught. The students could see the internal relationships between organs and structures, could rotate views and perform different cutting levels, so it was easy to understand how these structures related. Another advantage is the possibility of storing Anatomical information and images and comparing them on a computer with information from textbooks, atlases or web pages and videos [17].

In this article, based on objective data taken from the survey, we have to draw different conclusions about the low interest and usefulness of the Anatomage for students. They have experienced prossections and dissections as the most valuable, useful and interesting method of practical anatomy, surely because they can live anatomy and contact with the corpse as a real affair and a way of getting started in the practice of medicine. Looking for the causes of the low utility found by students in the Anatomage, we have observed that only 32 students complete the survey (half of all of them) so this is not a significant number of surveys. Perhaps some students may be disappointed by the practice of anatomy and were more interested in completing the survey, according to Pabst (2009), who affirms these same options [12]. Also during the last year the ratio of professors per number of students decreased and we have to share practice groups and we cannot schedule different practical activities with the Anatomage [18].

Anand, K.M and Singel, T. C. in 2017 [19] compared learning with "Anatomage" with dissection in neuroanatomy. No statistically significant differences in knowledge gain were observed between both methods. That is why "Anatomage" as a teaching-learning method is as good as traditional dissection. Learning with "Anatomage" facilitates 3D visualization of structures and their relationships. Recently on 2018, Memon, [20] after making a review of 200 full texts about the topics related to cadaver dissection in the past three decades wrote that cadaver dissection is obsolete in medical training. But at the end, he reached the conclusion that cadaver dissection is still a part of medical training in modified ways. Following Krishnaveni, S. et al. [21] small group teaching in the form of cadaveric dissection or demonstration is the method which the students feel is best to understand Anatomy. The modern methods of teaching anatomy with power point presentations or virtual anatomy are only a supportive methods to understand anatomy. Anatomage will offer in a short future the augmented reality eyepieces that can be used to overlay imaging of the patient over his or her actual body and anatomical structures will then be automatically recognised on the patient's body [22].

\section{Conclusion}

Proven opinions on the interest and usefulness of the different teaching methods of practical virtual anatomy will continue, with a difficult agreement, including dissections and anatomy. Without a doubt, a useful way to reconcile different opinions may be to take into account the opinion of the students. But, above all, by conducting objective studies (surveys, questionnaires, observational analyzes) 
administered at the beginning and end of the degree and at the graduate level. As explained in the studies carried out in different publications, about the results of the learning achieved with the different teaching methods of anatomy practices. And we must also have the opinion of the professionals of the Anatomy and other subjects that are part of the Medicine curriculum.

\section{Acknowledgement}

Natalio García Honduvilla, Ph.D. Department of Biomedical Sciences, Professor of Histology and director of the University Defense Center in Madrid, Faculty of Medicine and Health Sciences, University of Alcalá - 28047, Madrid, SPAIN, For giving me the opportunity to develop a practical and research work with the students of medicine and the use of Anatomage.

María Asunción Sánchez Gil, M.D. Medical Lieutenant Colonel, Secretary of the University Defense Center in Madrid, Faculty of Medicine and Health Sciences, University of 28047, Madrid, SPAIN, For her essential help to send and collect all the surveys to Medicine students.

\section{References}

1. Moxham BJ, Moxham SA (2007) The relationships between attitudes, course aims and teaching methods for the teaching of gross anatomy in the medical curriculum. Eur J Anat 11 (suppl 1): 19-30.

2. Ghosh, Sanjib K (2015) Human cadaveric dissection: a historical account from ancient Greece to the modern era. Anatomy \& Cell Biology 48 (3): 153-169.

3. Elizondo Omaña RE, Guzmán López S, García Rodríguez M de L (2005) Dissection as a teaching tool: past, present, and future.Anat Rec B New Anat 285(1):11-15.

4. Bergman EM (2015) Discussing dissection in anatomy education Perspect Med Educ 4(5): 211-213.

5. Riederer BM, Bueno López JL, Ayer R, Reblet C, Cadas H, et al. (2015) Practical teaching of preclinical anatomy Eur. J Anat 19 (2): 205-213.

6. Paech D, Giesel FL, Unterhinninghofen R, Schlemmer HP, Kuner T, et al. (2017) Cadaver-specific CT scans visualized at the dissection table combined with virtual dissection tables improve learning performance in general gross anatomy. Eur Radiol 27(5): 2153-2160.

7. Kažoka D, Pilmane M (2017) Teaching and learning innovation in present and future of human anatomy course at RSU. Papers on Anthropology 26(2): 44-52.

8. Patel KM, Moxham BJ (2006) Attitudes of professional anatomists to curricular change.Clin Anat 19(2): 132-141.

\section{ISSN: 2574-1241}

DOI: 10.26717/BJSTR.2020.24.004065

Jesús García Martín. Biomed J Sci \& Tech Res

(c) (P) This work is licensed under Creative

Submission Link: https://biomedres.us/submit-manuscript.php
9. Moxham BJ, Plaisant $O$ (2007) Perception of medical students towards the clinical relevance of anatomy. Clin Anat 20(5): 560-564.

10. Patel KM, Moxham BJ (2008) The relationships between learning outcomes and methods of teaching anatomy as perceived by professional anatomists. Clin Anat 21(2): 182-189.

11. Han ER, Chung EK, Nam KI (2015) Peer-Assisted Learning in a Gross Anatomy Dissection Course. PLoS ONE 10(11):

12. Pabst R (2009) Anatomy curriculum for medical students: What can be learned for future curricula from evaluations and questionnaires completed by students, anatomists and clinicians in different countries? Ann Anat 191(6): 541-546.

13. Duparc F (2017) 3D-Virtual Dissection Table: We did not imagine how much it will be useful for teaching anatomy and clinical anatomy. Rev Arg Anat Clin 9(1): 9-10.

14. Custer TM, Michael K (2015) The Utilization of the Anatomage Virtual Dissection Table in the Education of Imaging Science Students. J Tomogr Simul 1: 1-5.

15. García Martín J (2017) From virtual dissection to 3-D surgery simulation: The use of a computarized real body size table. Abstract of the Surgical Pathology \& Practice. March 27-28, 2017 Madrid, Spain 13th International Conference on Surgical Pathology \& Practice Surgery Curr Res 7(2 Suppl)

16. García Martín J, García Honduvilla N, Dankloff Mora C, Aguado Henche S (2018) From Virtual Dissection to 3-D Surgery Simulation. The Use of a Computerized Body-Size Table. BA0J Med Nursing 4: 048.

17. García Martín J, Dankloff Mora C, Aguado Henche S (2018) Possibilities for the use of Anatomage (the Anatomical Real Body-Size Table) for Teaching and Learning Anatomy with the Students. Biomed J Sci \&Tech Res 4(4).

18. García Martín J, Hernández Fernández LM, Sánchez Gil MA, García Honduvilla N (2019) Survey from students of military physician about different methods used to teach practical anatomy. Abstracts of the oral communications and posters presented during the International Congress of Anatomia Clinica. Surg Radiol Anat 41: 1227-1303

19. Anand MKTC Singel (2017) A comparative study of learning with "anatomage" virtual dissection table versus traditional dissection method in neuroanatomy. Ind J of Clin Anat and Physiol 2: 177-180.

20. Memon I (2018) Cadaver dissection is obsolete in medical training! a misinterpreted notion. Med Princ \& Pract 27 (3): 201-210.

21. Krishnaveni S, Rahe R, Johnson WMS (2019) Acomparative study on analysis of various teaching learning methodologies in anatomy. Int J Anat Res 7(4.1): 7029-7032.

22. Anatomage table. the future of anatomical education and more (2018) Anatomage Table Commission on the Future of Surgery-Contribution 1-8. Anatomage Table The Future of Anatomical Education and More.

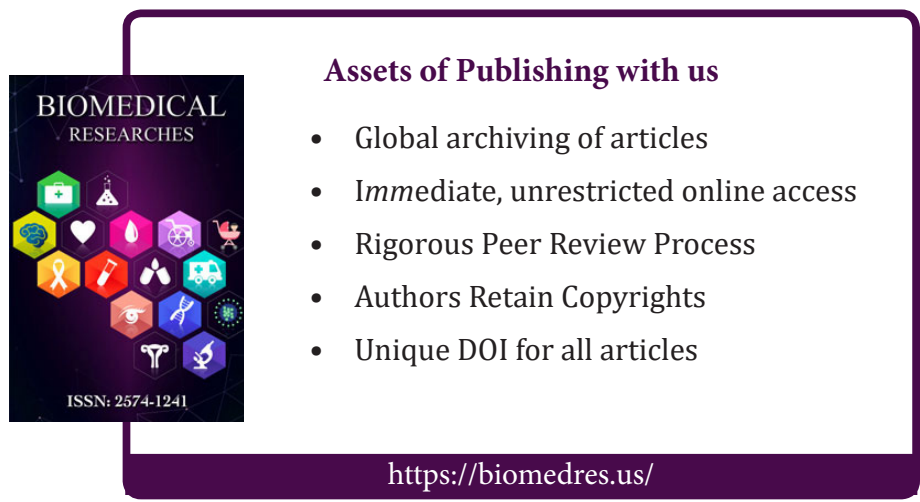

